\title{
Voxel-level biological optimisation of prostate IMRT using patient-specific tumour location and clonogen density derived from mpMRI
}

\author{
E. J. Her ${ }^{1 *}$ (D, A. Haworth' ${ }^{2}$, H. M. Reynolds $s^{3,4}$, Y. Sun ${ }^{3,4}$, A. Kennedy ${ }^{5}$, V. Panettieri' ${ }^{6}$, M. Bangert ${ }^{7,8}$, S. Williams ${ }^{3,9}$ and \\ M. A. Ebert ${ }^{1,5,10}$
}

\begin{abstract}
Aims: This study aimed to develop a framework for optimising prostate intensity-modulated radiotherapy (IMRT) based on patient-specific tumour biology, derived from multiparametric MRI (mpMRI). The framework included a probabilistic treatment planning technique in the effort to yield dose distributions with an improved expected treatment outcome compared with uniform-dose planning approaches.

Methods: IMRT plans were generated for five prostate cancer patients using two inverse planning methods: uniform-dose to the planning target volume and probabilistic biological optimisation for clinical target volume tumour control probability (TCP) maximisation. Patient-specific tumour location and clonogen density information were derived from mpMRI and geometric uncertainties were incorporated in the TCP calculation. Potential reduction in dose to sensitive structures was assessed by comparing dose metrics of uniform-dose plans with biologically-optimised plans of an equivalent level of expected tumour control.

Results: The planning study demonstrated biological optimisation has the potential to reduce expected normal tissue toxicity without sacrificing local control by shaping the dose distribution to the spatial distribution of tumour characteristics. On average, biologically-optimised plans achieved 38.6\% ( $p$-value: $<0.01)$ and $51.2 \%$ ( $p$-value: $<0.01)$ reduction in expected rectum and bladder equivalent uniform dose, respectively, when compared with uniformdose planning.

Conclusions: It was concluded that varying the dose distribution within the prostate to take account for each patient's clonogen distribution was feasible. Lower doses to normal structures compared to uniform-dose plans was possible whilst providing robust plans against geometric uncertainties. Further validation in a larger cohort is warranted along with considerations for adaptive therapy and limiting urethral dose.
\end{abstract}

Keywords: IMRT, Dose-painting, Tumour control probability, Multiparametric MRI, Probabilistic treatment planning

\footnotetext{
* Correspondence: emily.her@research.uwa.edu.au

${ }^{1}$ School of Physics, Mathematics and Computing, University of Western Australia, Perth, Australia

Full list of author information is available at the end of the article
}

(c) The Author(s). 2020 Open Access This article is licensed under a Creative Commons Attribution 4.0 International License, which permits use, sharing, adaptation, distribution and reproduction in any medium or format, as long as you give appropriate credit to the original author(s) and the source, provide a link to the Creative Commons licence, and indicate if changes were made. The images or other third party material in this article are included in the article's Creative Commons licence, unless indicated otherwise in a credit line to the material. If material is not included in the article's Creative Commons licence and your intended use is not permitted by statutory regulation or exceeds the permitted use, you will need to obtain permission directly from the copyright holder. To view a copy of this licence, visit http://creativecommons.org/licenses/by/4.0/ The Creative Commons Public Domain Dedication waiver (http://creativecommons.org/publicdomain/zero/1.0/) applies to the data made available in this article, unless otherwise stated in a credit line to the data. 


\section{Introduction}

During typical radiotherapy of prostate cancer (PCa), a uniform spatial distribution of a specific dose is prescribed to the entire prostate gland, without customisation of dose prescription and distribution to the actual characteristics of an individual's tumour. Spatial distributions of tumour characteristics may be accommodated in treatment planning through the use of non-invasive quantitative imaging. Several clinical trials that aimed to explore the feasibility of imaging-informed focal dose escalation and dose-painting have now completed (NCT01168479, NCT01208883, NCT01190527). Results of these studies are very promising $[8,37]$. Nevertheless, the ways in which quantitative imaging is used in treatment planning are variable and often fail to utilise the resulting information for objective dose prescription. Many studies applied a focal boost dose to sub-volumes identified as abnormal regions on quantitative images $[7,14,50,60]$, including the FLAME-trial [37]. However, the use of sub-volumes means discretisation of tumour characteristics such as clonogen density and hypoxia, whereas typically these characteristics vary continuously throughout the gland $[1,21$, $41,42,68]$. In studies where voxel-level information was utilised, simple linear relationships between image intensities and doses were frequently assumed [3, 14, 60], or non-validated dose prescription functions were used [4, 18, 31, 38, 48, 52, 65]. Ideal biological optimisation methods require accurately defined relationships between imaging parameter, derived radiobiological parameters and validated dose-response.

To utilise the full potential of quantitative imaging in treatment planning, biofocused radiotherapy (BiRT) of PCa using the spatial distribution of image-derived tumour characteristics has been proposed $[25,26]$. The proposed BiRT approach allows a simplified process of translating quantitative imaging to biologically-optimised plan using radiomics and machine learning methods. Machine learning methods, which generate voxel maps of tumour location and cell density from multiparametric magnetic resonance imaging (mpMRI), have recently been developed by our group [53, 54]. Using 'ground truth' histology information from a large patient database, reliable predictions from imaging can be made without the explicit understanding of underlying biological and physical processes. The voxel-level tumour information is then utilised in a tumour control probability (TCP) model that relates tumour characteristics and physical dose to the probability of tumour control. Voxel-level, patient-specific tumour information from mpMRI can be used to drive the treatment plan optimisation as model parameters to achieve a maximum TCP. Furthermore, a probabilistic treatment planning technique was adopted for biological optimisation to produce plans that are robust against geometric errors. In uniform-dose planning, a margin is used assuming that the clinical target volume (CTV) remains within the planning target volume (PTV) during irradiation in the presence of uncertainties. Therefore, giving a uniform prescription dose to a larger volume, i.e. the PTV, ensures that the prescription dose is delivered to the CTV. In contrast, the use of a margin to take account of is problematic for biological optimisation as the dose distribution is no longer uniform. Thus, probabilistic treatment planning, where the effect of geometric errors is incorporated in the expectation value of the TCP, was used to produce robust, biologically-optimised plans.

The potential of the proposed BiRT approach in producing superior treatment plans compared to conventional treatment has been demonstrated in low-dose-rate brachytherapy $[9,10,25]$ using population-based clonogen distribution information and segment-level TCP model. In the current study, the BiRT approach was extended to prostate intensity-modulated radiotherapy (IMRT) planning. The purpose of the study was to test the hypothesis that a biologically-optimised prostate IMRT plan, produced using the BiRT framework, can yield reduced dose to organs at risk (OAR) compared to the isoeffective uniform-dose plan.

\section{Methods \\ TCP model}

The TCP model has been described previously for a segmented prostate in a low-dose-rate brachytherapy application [23]. Here we describe the revised model to suit voxel-level information and fractionated external beam radiotherapy. The TCP was calculated for the CTV in this study.

The radiosensitivity parameter $\alpha$ was assumed to be lognormally distributed within a population [24, 29] with a mean, $\bar{\alpha}$, and a standard deviation, $\sigma_{\alpha}$. The TCP was computed using the following equation, where the distribution of $\alpha$ is normalised such that $\sum_{\mathrm{k}=1}^{\mathrm{p}} \mathrm{w}\left(\alpha_{\mathrm{k}}\right)=1$ with $p$ discrete samples:

$$
\mathrm{TCP}=\sum_{\mathrm{k}=1}^{\mathrm{p}} \mathrm{w}\left(\alpha_{\mathrm{k}}\right) \mathrm{TCP}\left(\alpha_{\mathrm{k}}\right)
$$

As a target volume consists of individual voxels, an assumption of voxel independence gives.

$$
\operatorname{TCP}\left(\alpha_{\mathrm{k}}\right)=\prod_{\mathrm{i}=1}^{\mathrm{N}} \mathrm{TCP}\left(\rho_{\mathrm{i}}, \alpha_{\mathrm{k}}, \mathrm{d}_{\mathrm{i}}\right)
$$

where $T C P_{i}$ represents the TCP of the $i^{\text {th }}$ voxel from a total of $N$ voxels. $d_{i}$ is the fractional dose to be delivered to voxel $i$ and $\rho_{\mathrm{i}}$ represents the corresponding voxel's clonogen density. 
The voxel TCP computed with $\alpha_{k}$ for a fractionated treatment is described by:

$$
\operatorname{TCP}_{\mathrm{i}}\left(\rho_{\mathrm{i}}, \alpha_{\mathrm{k}}, \mathrm{d}_{\mathrm{i}}\right)=\exp \left[-\rho_{\mathrm{i}} \mathrm{V}_{\mathrm{i}} \exp \left(-\alpha_{\mathrm{k}} \mathrm{nd}_{\mathrm{i}}-\frac{\alpha_{\mathrm{k}} \mathrm{nd}_{\mathrm{i}}^{2}}{\alpha / \beta}+\ln (2) \frac{\mathrm{T}_{\text {exp }}}{\mathrm{T}_{\text {pot }}}\right)\right]
$$

where $\mathrm{V}_{\mathrm{i}}$ represent the volume of voxel $i . \alpha / \beta$ is the alpha/beta ratio of PCa and $n$ is the number of fractions, which was 39 fractions in this study with a prescription dose of $78 \mathrm{~Gy}$. The presence of accelerated proliferation in PCa is still unclear with conflicting results on the effect of overall treatment time on treatment outcome [5, $19,20,33,46,63,64]$. While there may be a slight and gradual increase in repopulation with time, it is unlikely to have a significant effect as that seen in head and neck cancers. Therefore, accelerated repopulation was ignored. Clonogenic repopulation component consisted of overall treatment time, $T_{\text {exp }}$, and potential doubling time, $T_{p o t} . T_{\exp }$ was approximated as $1.4 n$ assuming daily fractions to be delivered during the working week. The following model parameters were derived from the work of Wang et al. [63]: $\bar{\alpha}=0.15 \mathrm{~Gy}^{-1}, \sigma_{\alpha}=0.04 \mathrm{~Gy}^{-1}, \alpha / \beta=3.1$, and $\mathrm{T}_{\text {pot }}=42$ days).

\section{Data acquisition}

A subset of five consecutive patients was selected from a cohort of PCa patients who participated in a Human Research Ethics Committee approved project (Reference number: HREC/15/PMCC/125) at the Peter MacCallum Cancer Centre, Melbourne, Australia. Informed written consent was obtained from all patients, and all underwent radical prostatectomy for their PCa management. Patient demographics are summarised in Table 1.

Machine learning methods have previously been developed to generate a Gaussian kernel support vector machine to predict tumour location and a general additive model to predict cell density $[53,54]$. The pipeline involved the collection of in vivo mPMRI data prior to prostatectomy. MR sequences included T2-weighted, diffusion-weighted, dynamic contrast-enhanced magnetic resonance imaging (MRI) and blood-oxygen-leveldependent sequences. After prostatectomy, ex vivo MRI data were obtained from the specimens to aid coregistration of ground truth histology with mpMRI.
Histology slides obtained at $5 \mathrm{~mm}$ intervals were annotated with tumour location and grade by an expert pathologist. Predictive models were fitted to ground truth histology and corresponding mpMRI parameters. Detailed information on the MR sequences, image registration techniques and machine learning methods used in the production of tumour biology prediction maps are contained in Reynolds et al. [49], Sun et al.[53] and Sun et al. [54].

Using the developed methods, patient-specific, voxellevel tumour location and cell density per area (number of cells $/ \mathrm{mm}^{2}$ ) prediction maps were generated from mpMRI data for the five patients selected for this study.

The resolution of the tumour location and cell density per area prediction maps were $0.22 \mathrm{~mm} \times 0.22 \mathrm{~mm} \times 2.5$ $\mathrm{mm}$. To allow reduced computation time during treatment planning, the prediction maps were resampled to a voxel size of $2 \mathrm{~mm} \times 2 \mathrm{~mm} \times 2.5 \mathrm{~mm}$.

\section{Clonogen distribution maps}

The cell density per area prediction maps were then converted into volumetric cell density maps (number of cells/ $\mathrm{mm}^{3}$ ) by raising each voxel value to the power of $3 / 2$. Uniform cell density per area was assumed between slices. Each voxel in the tumour location prediction maps contained a continuous value between 0 and 1 , representing the probability of the voxel containing tumour cells. For each patient, a threshold probability that maximised the sum of sensitivity and specificity of the receiver operating characteristics curve was selected by testing each threshold (to the nearest 0.01 ) incrementally. The selected threshold was then used to create a binary tumour location prediction map.

The matching binary tumour location prediction map and cell density prediction map were then multiplied together for each patient to generate a patient-specific cell distribution map. As the cell density prediction map is unable to distinguish between normal cells and tumour cells, the cell distribution maps were linearly scaled such that the median total number of cells within the prostate of the five patients was equal to $10^{7}$. This value represents the estimated total clonogen number of high-risk PCa patients from a study by Wang et al. [63]. Linearly scaled cell distribution maps are now referred to as clonogen distribution maps. Original and scaled cell numbers for all five patients are summarised in Table 2.

Table 1 Patient demographics

\begin{tabular}{lllll}
\hline Patient number & Age (years) & PSA $(\mathrm{ng} / \mathrm{mL})$ & Gleason score of the dominant nodule & Pathological stage \\
\hline 1 & 59 & 16 & $7(4+3)$ & PT3a \\
2 & 68 & 27 & $9(5+4)$ & PT3b N0 \\
3 & 68 & 10.5 & $7(4+3)$ & pT3a \\
4 & 10 & $7(3+4)$ & PT2c \\
5 & 71 & 11 & $7(4+3)$ & pT3a \\
\hline
\end{tabular}




\section{Treatment planning}

Treatment planning was performed using a MATLAB based open-source program, matRad (German Cancer Research Centre, Heidelberg, Germany, version 1.4 beta) $[12,66]$. matRad simulates a $6 \mathrm{MV}$ linear accelerator beam using pre-calculated kernels for beam elements for user-defined beam angles. Beam element weightings are optimised by a gradient descent algorithm (version 1.4 beta) incorporating direct aperture optimisation. The original code was modified to include the biological optimisation functions and voxel-level model parameters. matRad was executed using MATLAB (version 2018b, The MathWorks Inc., Massachusetts, USA). The beamlet width was $2.5 \mathrm{~mm}$ and a 7-field beam geometry $\left(0^{\circ}\right.$, $40^{\circ}, 80^{\circ}, 110^{\circ}, 250^{\circ}, 280^{\circ}, 310^{\circ 1}$ ) was used.

Computed tomography (CT) images were not acquired as part of the imaging protocol described in Data acquisition. For treatment planning, a single CT image set from an established clinical trial was selected. The selection was based on the union of the CT-defined CTV and each of the delineated CTV structures from the T2-weighted MRI of the five patients. The CTV in this study was defined as the entire prostate gland, excluding the seminal vesicles, according to ICRU Report 62 [34]. The MRI-CTV was delineated by an experienced radiation oncologist (SW). The CT image set and prediction maps were manually registered individually so that each MRI-CTV structure was completely contained within the CT-defined CTV.

\section{Uniform-dose plan}

The standard approach to account for uncertainties in uniform-dose planning is to apply a treatment margin to the CTV to produce the PTV. Hence for this study, we have applied a margin based on the work of van Herk et al. [27] for uniform-dose plans to account for robustness. The following formula ensures the minimum dose to the CTV is $95 \%$ of the prescription dose for $90 \%$ of the patients:

$$
\text { Margin }=2.5 \Sigma+0.7 \sigma
$$

where $\Sigma$ and $\sigma$ represent the standard deviation of systematic and random components of geometric errors, respectively. Sources of systematic error considered in this study were target delineation and intrafraction motion [2, 32]. Treatment accuracy is also limited by fiducial marker localisation. It was assumed that systematic errors were isotropically distributed with a zero mean. A random error is any deviation that can vary in direction and magnitude for each treatment fraction. The random effect of intrafraction motion was considered in this study [32]. Sources of geometric errors and their distributions are summarised in Appendix 1. The overall geometric error distribution in

\footnotetext{
${ }^{1}$ International Electrochemical Commission definitions
}

Table 2 The original and scaled total cell number (clonogen) for each patient

\begin{tabular}{lll}
\hline Patient & \multicolumn{2}{l}{ Total cell number in CTV } \\
\cline { 2 - 3 } & $\begin{array}{l}\text { Original } \\
\text { (normal + clonogen) }\end{array}$ & $\begin{array}{l}\text { Scaled } \\
\text { (clonogen) }\end{array}$ \\
\hline 1 & $1.81 \mathrm{E}+08$ & $1.00 \mathrm{E}+07$ \\
2 & $5.41 \mathrm{E}+08$ & $2.99 \mathrm{E}+07$ \\
3 & $2.22 \mathrm{E}+07$ & $1.23 \mathrm{E}+06$ \\
4 & $3.83 \mathrm{E}+08$ & $2.12 \mathrm{E}+07$ \\
5 & $5.93 \mathrm{E}+07$ & $3.28 \mathrm{E}+06$ \\
\hline
\end{tabular}

each of the three principal directions with the calculated margin are summarised in Table 3.

The dose-volume (DV) constraints and objective functions for the target volumes and OARs are summarised in Table 4. A mathematical formulation of each objective function is given in Appendix 2. The generated uniform-dose plans required PTV V74Gy (95\% prescription dose) $\geq 99 \%$ and CTV V78Gy (100\% prescription dose) $\geq 99 \%$. The resulting uniform-dose plan is called Plan A.

\section{Biologically-optimised plan}

For biological optimisation, probabilistic treatment planning technique was utilised where the effects of treatment are incorporated in the optimiser. The target objective was to maximise the expectation value of TCP. Two types of uncertainties were considered to derive robust treatment plans. The first was the uncertainty in radiosensitivity parameter, $\alpha$, of the TCP model due to inter-patient variability. The radiosensitivity heterogeneity was applied for all patients as a log-normal distribution within a population in the calculation of TCP, as described in Eq. 1.

The second type of treatment uncertainty considered was geometric uncertainties. These were identical to those considered for uniform-dose plans with additional uncertainties introduced in MR-histology and MR-CT registration steps $[13,15,45,49]$. Their distributions are also summarised in Appendix 1. Geometric uncertainties were integrated into the TCP objective function for biological inverse planning using the methods described in Witte et al. [67]. It was assumed that the effects of random error could be approximated by blurring the dose distribution. The effects of systematic error were approximated by the translation of the patient volume with respect to the dose matrix. The dose distribution was assumed to not change as a result of the translation and rotations were not considered. From Eqs. (1) and (2), the expectation value of $\mathrm{TCP},\langle\mathrm{TCP}\rangle$, can be written as:

$$
\langle T C P\rangle=\sum_{k=1}^{p} \mathrm{w}\left(\alpha_{\mathrm{k}}\right)\left\langle\mathrm{TCP}\left(\alpha_{\mathrm{k}}\right)\right\rangle
$$


Table 3 The overall treatment uncertainty distribution with the calculated margin (in $\mathrm{mm}$ ) in three principal directions. $M=$ mean, $\Sigma=$ standard deviation of systematic errors, $\sigma=$ standard deviation of random errors

\begin{tabular}{lllll}
\hline Direction & M & $\Sigma$ & $\boldsymbol{\sigma}$ & Margin \\
\hline AP & -0.4 & 2.56 & 1.26 & 7.3 \\
LR & 0.2 & 2.47 & 0.67 & 6.6 \\
SI & 0.1 & 2.58 & 1.18 & 7.3 \\
\hline
\end{tabular}

$$
\left\langle T C P\left(\alpha_{k}\right)\right\rangle=\sum_{j} G_{S y s, j} \prod_{i}^{N} T C P_{i}\left(\rho_{i, j}, \alpha_{k},\left(G_{\text {rand }} \otimes d\right)_{i}\right)
$$

$G_{\text {Sys }}$ and $G_{\text {rand }}$ are the Gaussian probability density functions of systematic and random errors. The summation of the overall TCP over $j$ denotes integration over systematic errors. For simplicity, the value of TCP that has been integrated with probability density functions of is called an expectation or expected value of TCP. However, it should be noted that strictly speaking, this method developed by Witte et al. [67] calculates an approximation of the expected value under systematic and random uncertainties.

For OARs, identical dose- and DV-based constraints to uniform-dose plans (Table 4) were applied except that the expectation value of dose was substituted for absolute dose. Biologically-optimised plans required CTV < V78Gy> (volume receiving expected dose greater than or equal to $78 \mathrm{~Gy}) \geq 99 \%$. The resulting biologicallyoptimised plans are now called Plan B.

\section{Plan evaluation and comparison of uniform-dose and biologically-optimised dose distributions}

Uniform-dose plans (Plan A) and biologically-optimised plans (Plan B) of equal $\langle\mathrm{TCP}\rangle$ were compared by evaluating dose metrics in the five patients. To calculate < $\mathrm{TCP}>$, the patient-specific clonogen distribution map was used. The corresponding sources of geometric uncertainties considered each treatment planning method was used in the $<\mathrm{TCP}>$ calculation.

The plans were then linearly scaled to generate a dose distribution with $\mathrm{a}<\mathrm{TCP}>$ of 0.95 to allow comparison of dose to OARs between plans at the same level of expected control. A very small variation between the scaled dose distribution and the optimal solution with equal < $\mathrm{TCP}>$ was expected, hence we have assumed invariance of the optimal solution with dose scaling. This scaling approximates the dose escalation required to achieve equivalent tumour control, assuming any effort to reduce OAR dose at such an escalated dose would be counterproductive. Clinically relevant DV parameters and the expectation value of generalised equivalent uniform dose [43], the dose that when homogeneously given yields the same biological effect as the nonuniform dose, were calculated for the rectum and bladder. Similar to $\langle\mathrm{TCP}\rangle$, the expectation value of generalised equivalent uniform dose, $\langle$ EUD $>$, was computed by approximating the effects of systematic and random error using their probability density functions:

$$
\langle E U D\rangle=\sum_{j} G_{s y s, j}\left[\frac{1}{N} \sum_{i}^{N}\left(G_{\text {rand }} \otimes D\right)_{i, j}^{a}\right]^{1 / a}
$$

where $a$ is a tissue-specific parameter $\left(a_{\text {rectum }}=6, a_{\text {blad- }}\right.$ der $=6)$ and $D_{i}=n d_{i}$. For simplicity, we assumed that the shape of the rectum and bladder were invariant and that both OARs had the same intrafraction organ motion as the prostate. Mean dose to the head of femurs (HOF) and the integral energy was also determined.

Paired t-tests were performed for the comparison between dose and DV parameters of isoeffective Plans A and $B$, with the $R$ statistical language ( $R$ Foundation for Statistical Computing, Austria, Version 3.2.3). A test statistic $(p)$ less than 0.05 was considered significant.

\section{Results}

The optimised dose distributions on identical axial slices for Plans $\mathrm{A}$ and $\mathrm{B}$ are presented for Patient 1 in Fig. 1.

Table 4 Dose-volume constraints and objective functions used in uniform-dose planning. + = Quantitative Analyses of Normal Tissue Effects in the Clinic (QUANTEC). *Radiation Therapy Oncology Group (RTOG) Consensus. Square deviation function penalises any deviation from the reference dose, $D_{\text {ref, }}$ whereas square overdose function penalises doses greater than $D_{\text {ref. }}$ Mathematical

\begin{tabular}{|c|c|c|c|}
\hline Volume of interest & DV constraint & Objective function & Function parameter(s) \\
\hline$\overline{C T V}$ & V78Gy $\geq 99 \%$ & Square deviation & $D_{\text {ref }}=78 \mathrm{~Gy}$ \\
\hline $\begin{array}{l}\text { Rectum }^{\dagger} \\
{[39]}\end{array}$ & $\begin{array}{l}\text { V50Gy } \leq 50 \% \\
\text { V60Gy } \leq 25 \%\end{array}$ & DV & $\begin{array}{l}D_{\text {ref } 1}=50 \mathrm{~Gy} \text { and } V_{\text {ref }}=50 \%, \\
D_{\text {ref } 1}=60 \mathrm{~Gy} \text { and } V_{\text {ref }}=25 \%\end{array}$ \\
\hline $\begin{array}{l}\text { Bladder }^{\dagger} \\
\text { [61] }\end{array}$ & V65Gy $\leq 50 \%$ & DV & $\mathrm{D}_{\mathrm{ref} 1}=65 \mathrm{~Gy}$ and $\mathrm{V}_{\text {ref }}=50 \%$ \\
\hline $\begin{array}{l}\text { Left and right head of femurs (HOF) } \\
\text { [36] }\end{array}$ & V $50 G y \leq 5 \%$ & DV & $D_{\text {ref } 1}=50 \mathrm{~Gy}$ and $V_{\text {ref }}=5 \%$ \\
\hline External volume & - & Square overdose & $\mathrm{D}_{\text {ref }}=$ Variable to avoid hotspc \\
\hline
\end{tabular}
formulations of the objective functions are summarised in Appendix 2 


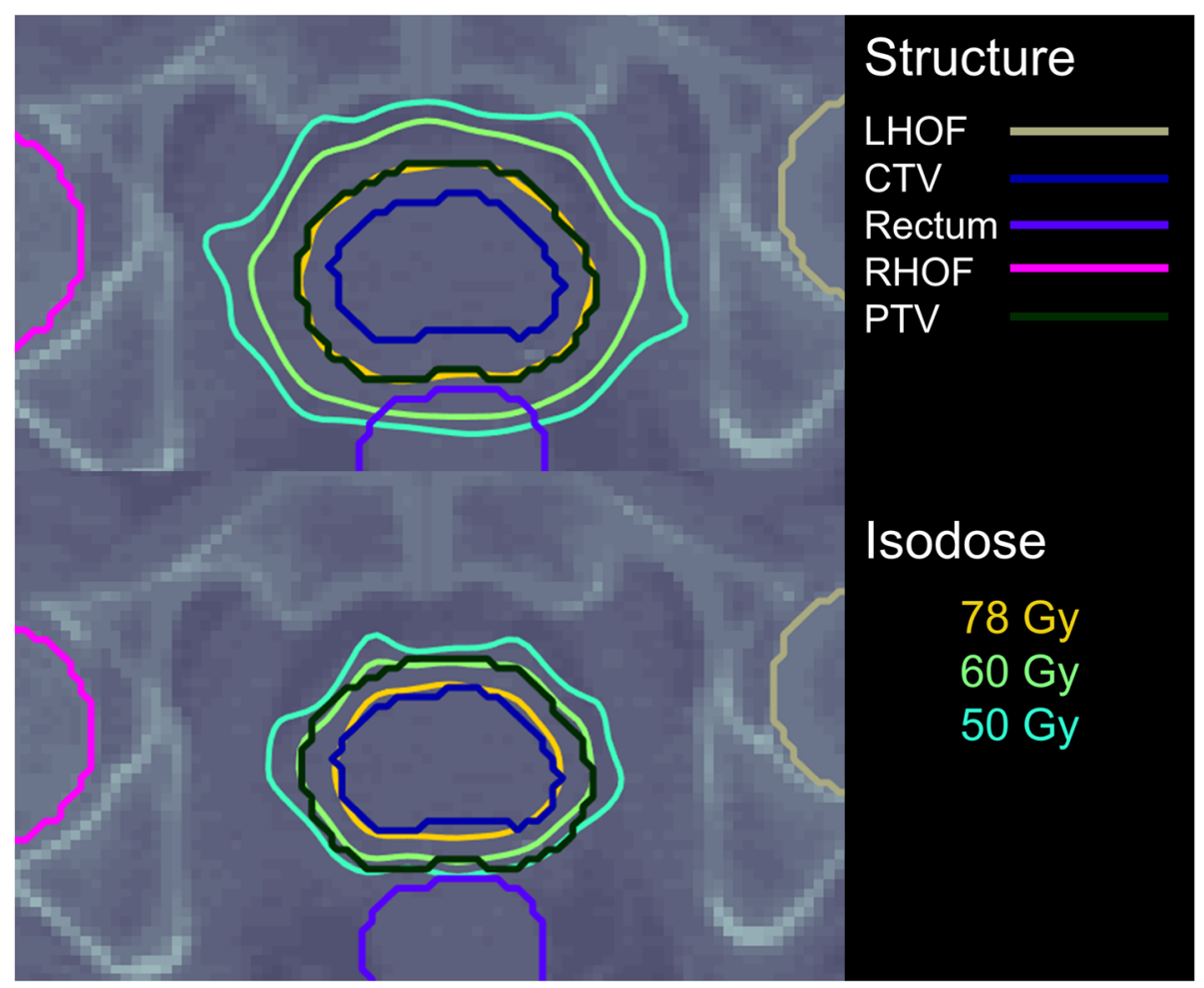

Fig. 1 Isodose distributions for Patient 1. Above: Uniform-dose plan, Plan A. Below: Biologically-optimised plan, Plan B. Isodose distributions for other patients are available in the supplementary document

The corresponding clonogen distribution maps, CTV dose and $\langle\mathrm{TCP}\rangle$ distributions are displayed in Fig. 2. Resulting dose metrics of each plan are summarised in Table 5.

With biological optimisation, higher dose to the CTV ( $p$-value: <0.01) was achieved with significantly lower < EUD $>$ to the rectum ( $p$-value: $<0.01)$ and bladder $(p$ value: <0.01) for the isoeffective uniform-dose plans (Table 5 and Fig. 3) and well within the dose constraints. Plan B demonstrated substantial improvement in rectal and bladder NTCP. Due to a high variance in NTCP values for Plan A, attributed to high sensitivity of the model in the given $<$ EUD $>$ range, statistical significance could not be demonstrated (available in the supplementary document). A statistically significant reduction in mean doses to the HOFs was achievable $(p$-value: $<0.01)$. It is also evident from that biological optimisation was successful in modulating the beam intensities within the CTV, following the required dose dictated by the varying clonogen densities whilst accounting for treatment uncertainties. As a result, on average, biologically-optimised Plan B achieved $16.3 \%$ greater $\langle\mathrm{TCP}>$ than Plan A $(p-$ value: 0.02 ). The biofocused approach improved the < $\mathrm{TCP}>$ by directly incorporating $\langle\mathrm{TCP}>$ evaluation in the treatment plan optimisation algorithm. Plan B could achieve a significantly higher $\langle\mathrm{TCP}\rangle$ in all five patients, by increasing the value of individual voxel $\langle\mathrm{TCP}\rangle$ and $<$ TCP> homogeneity (Fig. 2 and Fig. 4).

\section{Discussion}

A framework for optimising prostate IMRT with mpMRIderived patient-specific tumour characteristics with probabilistic treatment planning technique has been presented. Uniform-dose and biologically-optimised IMRT plans for five patients were generated and compared. Whilst our sample size was small, this study illustrated the potential advantage of biological optimisation in yielding an improved expected probability of tumour control while achieving better sparing of OARs. Future studies will incorporate a larger sample size with a range of tumour volumes and tumour position within the prostate to assess the variation in benefit of the proposed approach. It is anticipated that these studies will identify key clinical features that will predict the benefit of the proposed BiRT approach.

Under the assumption of voxel independence, a maximum TCP is attained when the TCP for the individual voxels across the PTV are high and spatially homogeneous [17]. In the presence of tumour heterogeneity due to varying clonogen density or other relevant parameters, a uniform-dose distribution will have a highly non-uniform TCP distribution (Fig. 2 (iv)). By directly incorporating TCP in treatment planning optimisation, the ability of 

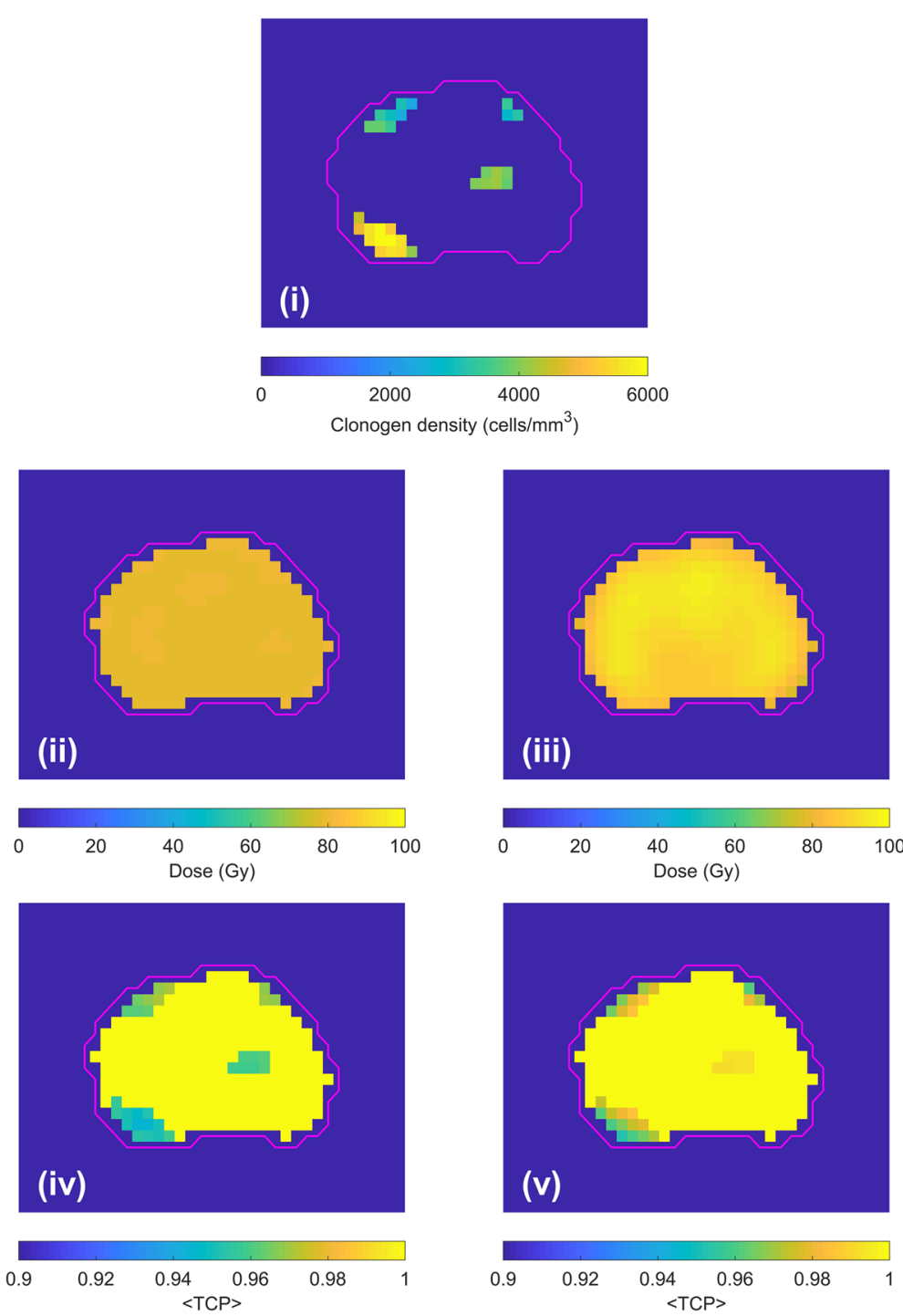

Fig. 2 Treatment plan data for Patient 1. Axial slice corresponds to Fig. 1. Magenta contour represents the CTV. (i) clonogen distribution map. (iiiii) CTV dose distribution of the Plans A and B. (iv-v) Corresponding $\langle\mathrm{TCP}\rangle$ distribution of the Plans A and B. Results for all patients are available in the supplementary document

IMRT to modulate the beam intensity within the CTV is realised (Fig. 2 (v)). An increase in dose inhomogeneity was observed in the biologically-optimised plans (Plan B). On average, Plan B demonstrated a 11-percentage point improvement ( $p$-value:0.02) in $<\mathrm{TCP}>$ compared to Plan A which was based on physical dose optimisation. A relatively lower $\langle\mathrm{TCP}\rangle$ around the periphery of the CTV is most likely due to the physical restriction of the IMRT dose gradient. The ability to modulate beam intensity with clonogen distribution allowed a lower dose to the rectum and bladder in pursuit of the overall tumour control objective. When Plans A and B with an equal $<\mathrm{TCP}>$ of 0.95 were compared, Plan B demonstrated 38.6\% ( $p$-value:< $0.01)$ and $51.2 \%(p$-value: $<0.01)$ reduction in rectum and bladder <EUD>, on average. With full-biological optimisation where probabilistic objectives such as < NTCP $>$ and $<$ EUD $>$ minimisation are applied to rectum and bladder, a treatment plan with minimal predicted tissue toxicity could be achieved.

The standard of care of PCa with IMRT is moving away from uniform-dose planning with the progressive evolvement of quantitative imaging. Dose escalation in regions informed by imaging is becoming more common in the clinical setting. However, the majority of the doseescalation is applied to sub-volumes that are manually contoured based on image intensity, leading to large variations in sub-volumes [51]. To overcome this limitation, investigators used a dose-painting-by-numbers technique where the dose prescription is applied at the voxel level [6, $8,14,16,22,44,52,57,69]$. Rather than using a dose- 
Table 5 Dose parameters for isoeffective Plans A and B. Dose distributions of the plans were scaled to achieve equivalent tumour control $(\langle T C P\rangle=0.95)$

\begin{tabular}{|c|c|c|c|c|c|c|c|c|c|c|c|c|c|}
\hline \multicolumn{2}{|c|}{ Dose parameters } & \multicolumn{2}{|c|}{ Patient 1} & \multicolumn{2}{|c|}{ Patient 2} & \multicolumn{2}{|c|}{ Patient 3} & \multicolumn{2}{|c|}{ Patient 4} & \multicolumn{2}{|c|}{ Patient 5} & \multirow{2}{*}{$\begin{array}{l}\text { Mean absolute } \\
\text { change } \\
\text { (mean \% change) }\end{array}$} & \multirow[t]{2}{*}{$p$} \\
\hline & & Plan A & Plan B & Plan A & Plan B & Plan A & Plan B & Plan A & Plan B & Plan A & Plan B & & \\
\hline$\langle\mathrm{TCP}\rangle$ & & 0.70 & 0.75 & 0.60 & 0.73 & 0.84 & 0.88 & 0.61 & 0.78 & 0.75 & 0.90 & $\begin{array}{l}+0.11 \\
(+16.3 \%)\end{array}$ & 0.02 \\
\hline \multirow[t]{10}{*}{$\begin{array}{l}\langle\mathrm{TCP}\rangle=0.95 \\
\text { scaled }\end{array}$} & $\begin{array}{l}\text { CTV } \\
D_{\text {mean }}(G y)\end{array}$ & 100.0 & 108.3 & 104.2 & 112.0 & 91.9 & 103.8 & 102.9 & 115.0 & 95.8 & 101.6 & $\begin{array}{l}+9.2 \\
(+9.3 \%)\end{array}$ & $<0.01$ \\
\hline & $\begin{array}{l}\text { PTV } \\
D_{\text {mean }}(G y)\end{array}$ & 100.0 & 88.9 & 104.2 & 93.4 & 91.9 & 87.1 & 103.0 & 91.7 & 95.8 & 86.2 & $\begin{array}{l}-9.5 \\
(-9.5 \%)\end{array}$ & $<0.01$ \\
\hline & $\begin{array}{l}\text { Rectum } \\
\text { V60 (\%) }\end{array}$ & 4.4 & 0.2 & 3.2 & 0.1 & 1.1 & 0.0 & 1.0 & 0.0 & 1.6 & 0.2 & $\begin{array}{l}-2.2 \\
(-96.0 \%)\end{array}$ & 0.03 \\
\hline & $\begin{array}{l}\text { Rectum } \\
\text { V50 (\%) }\end{array}$ & 6.7 & 0.7 & 4.8 & 0.6 & 2.4 & 0.1 & 1.8 & 0.1 & 2.6 & 0.4 & $\begin{array}{l}-3.3 \\
(-90.4 \%)\end{array}$ & 0.01 \\
\hline & $\begin{array}{l}\text { Bladder } \\
\text { V65 (\%) }\end{array}$ & 3.1 & 0.0 & 1.9 & 0.0 & 3.1 & 0.0 & 0.8 & 0.0 & 2.6 & 0.0 & $\begin{array}{l}-2.3 \\
(-100 \%)\end{array}$ & $<0.01$ \\
\hline & $\begin{array}{l}\text { Rectum } \\
\langle\text { EUD }\rangle \text { (Gy) }\end{array}$ & 47.7 & 29.1 & 45.5 & 27.1 & 35.1 & 22.2 & 36.4 & 21.5 & 39.9 & 25.6 & $\begin{array}{l}-15.8 \% \\
(-38.6 \%)\end{array}$ & $<0.01$ \\
\hline & $\begin{array}{l}\text { Bladder } \\
\langle\text { EUD }\rangle \text { (Gy) }\end{array}$ & 46.9 & 21.9 & 43.4 & 22.8 & 44.0 & 23.1 & 36.2 & 14.1 & 43.7 & 23.3 & $\begin{array}{l}-21.8 \\
(-51.2 \%)\end{array}$ & $<0.01$ \\
\hline & $\begin{array}{l}\text { Left HOF } \\
D_{\text {mean }}(G y)\end{array}$ & 22.7 & 18.0 & 22.4 & 15.8 & 21.8 & 14.0 & 22.3 & 13.1 & 22.4 & 16.0 & $\begin{array}{l}-6.9 \\
(-31.2 \%)\end{array}$ & $<0.01$ \\
\hline & $\begin{array}{l}\text { Right HOF } \\
D_{\text {mean }}(G y)\end{array}$ & 20.7 & 14.7 & 21.1 & 12.1 & 20.0 & 13.8 & 19.9 & 11.3 & 21.2 & 13.5 & $\begin{array}{l}-7.5 \\
(-36.4 \%)\end{array}$ & $<0.01$ \\
\hline & $\begin{array}{l}\text { Integral energy } \\
\left(\times 10^{6} \mathrm{~J} / \mathrm{cm}^{3}\right)\end{array}$ & 10.00 & 6.05 & 9.45 & 5.56 & 9.30 & 5.95 & 9.14 & 4.99 & 9.57 & 5.78 & $\begin{array}{l}-3.8 \\
(-40.3 \%)\end{array}$ & $<0.01$ \\
\hline
\end{tabular}

prescription approach, we have applied a voxel-level TCP objective function to incorporate the expected treatment outcome. Furthermore. unlike previous studies that assumed clonogens are evenly distributed within the tumour or that all patients have an identical number of clonogens and/or radiosensitivity $[16,57,58,67]$, the proposed BiRT approach accounts for tumour heterogeneity derived from mpMRI.

The proposed biofocused approach provides robust solutions by incorporating treatment-related uncertainties in the optimisation process. In this study, the expectation value of TCP was optimised using the method developed by Witte et al. [67]. Probabilistic treatment planning techniques remove the need for expansion of CTV into PTV and have demonstrated improved robustness to margin-based treatment planning methods [11, 40, $59,62]$. However, there are limitations to overcome before clinical implementation of margin-less probabilistic treatment planning becomes a reality. As with all probabilistic treatment planning, the accuracy of geometric uncertainty distributions is critical to the treatment outcome, even more so than those associated with radiobiological models [67]. Since a sharp dose gradient is dictated by the probabilistic approach [67] as well as an inhomogeneous clonogen distribution, an underestimation of the geometric errors, especially the systematic component, may result in treatment failure. While the current work adopted a complete margin-less approach, a small margin may be necessary to accommodate uncertainties that were not considered. There may be clonogens outside of the CTV due to nodal involvement or other geometric uncertainties that have not been accounted for. Probabilistic treatment planning is also more computationally intensive than dose-based methods due to complex objective functions. To speed up the process, a compromise had to be made in the computation matrix resolution which was initially planned for $1 \mathrm{~mm} \times 1 \mathrm{~mm} \times 2.5 \mathrm{~mm}$ but reduced to 2 $\mathrm{mm} \times 2 \mathrm{~mm} \times 2.5 \mathrm{~mm}$. Similarly, Witte et al. used a 4 $\mathrm{mm} \times 4 \mathrm{~mm} \times 4 \mathrm{~mm}$ dose grid to enable faster computation process. As the cost of computing power is reduced, it is expected that probabilistic biological optimisation will be widely adopted while preserving high-resolution data provided by quantitative and multiparametric imaging.

The utilised TCP model has limitations in describing the complex nature of dose-response. Our model assumes the distribution of clonogen density remains constant during the treatment when it is expected to change as treatment progresses in reality. Methods to monitor such response are currently unavailable, however, studies are underway (for example Clinical trial ANZCTR UTN U1111-12219589) to investigate the potential to model such response using mpMRI. With this information, the TCP model could 


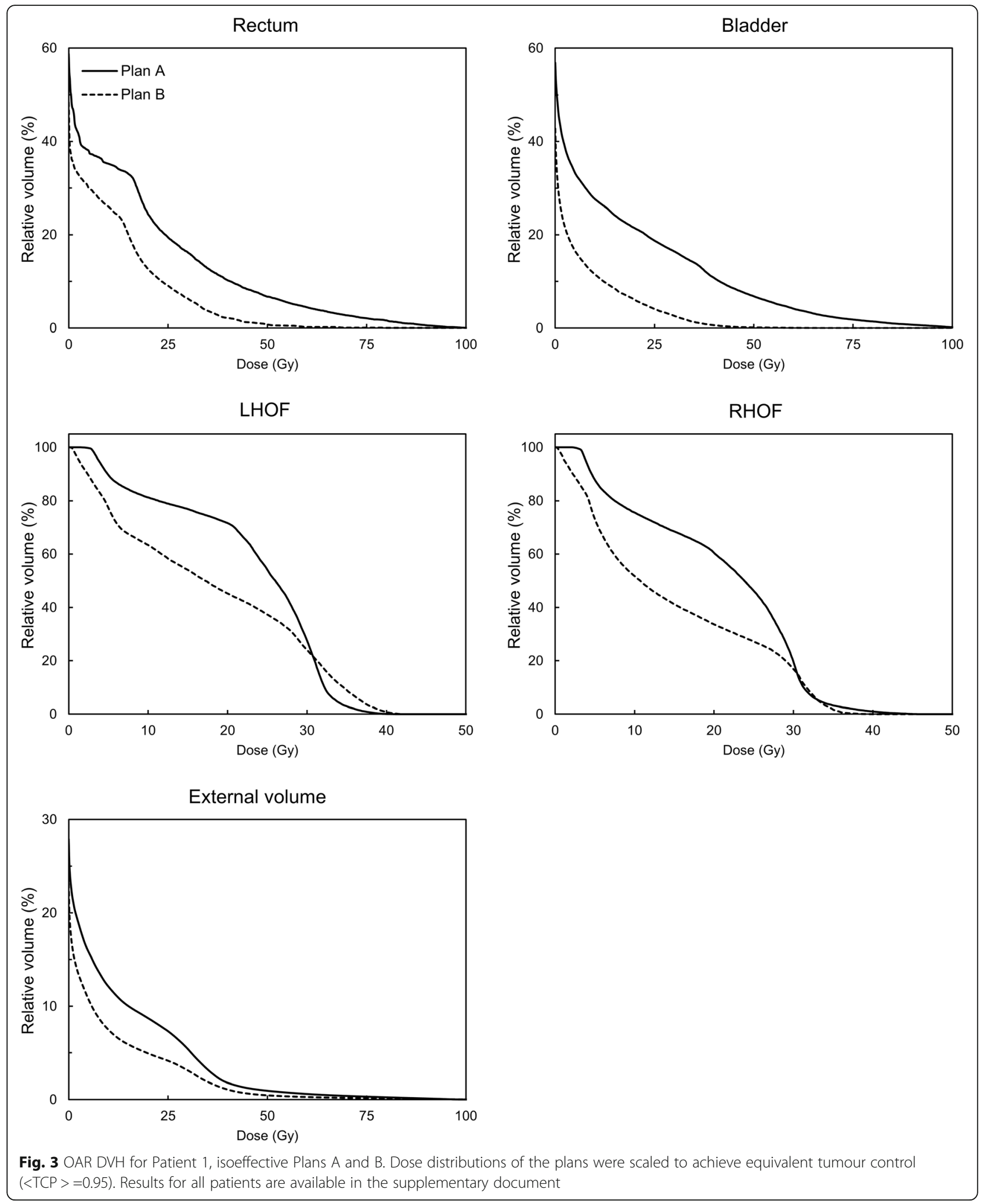

be extended to account for changes in tumour biology characteristics in response to treatment. Our TCP model similarly excludes the effect of hypoxia, in model parameters and the inherent assumption that all clonogens must be eradicated to achieve tumour control in the absence of reliable information available for modelling. Thus, 


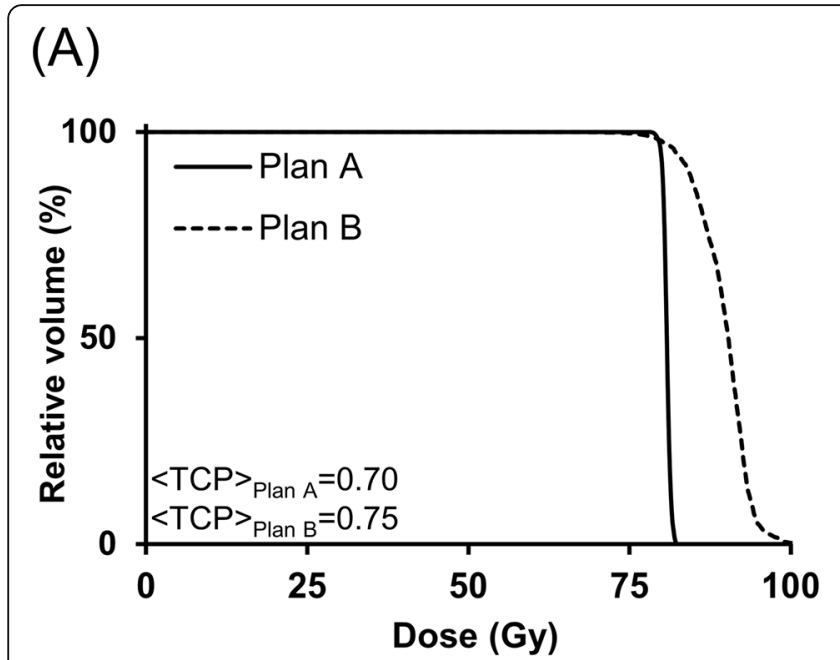

(B)

Fig. 4 (A) CTV DVH and (B) <TCP >-volume histogram for Plans A and B of Patient 1

the calculated TCP values can only be considered in the relative rather than absolute sense. Therefore, whilst a better outcome is predicted in biologically-optimised plans when compared with the uniform-dose approach, the absolute probability of tumour control cannot be quantified in this study. The uncertainty in radiosensitivity parameter, $\alpha$, arising from inter-patient variability was accounted for applying a log-normal population distribution. In practice, inter- and intra-tumour heterogeneity in radiosensitivity for the individual patient will be presented in the form of a 3D biological map containing a distribution of Gleason score and hypoxia throughout the tumour generated from mpMRI using biomarkers formulated by Sun et al. $[55,56]$.

Uncertainties in the models to predict tumour location and cell density have been previously quantified [53, 54]. Tumour location threshold uncertainty was found to have an insignificant effect on the total clonogen number. Cell density has a linear relationship with TCP between the range defined by the $95 \%$ confidence intervals of the parameter. Hence, the predicted clonogen density values were considered as the expected values and no further data manipulation was performed to incorporate the uncertainties in clonogen density prediction map.

Furthermore, this study did not consider the urethra in treatment planning optimisation. Despite advances in dose delivery techniques, urethral strictures remain one of the most serious side-effects of prostate radiotherapy $[28,30$, 35,47 , with reported incidences up to $20 \%$ [28]. As the urethra could not be easily delineated in the MR datasets, it was not possible to spare the urethra in the optimisation process. Future studies will model the urethra position using the ground truth histology from the BiRT cohort, and hence urethra sparing techniques may be possible. A randomized clinical trial that aimed to spare the MRIdefined urethra in prostate IMRT failed to improve urinary quality of life (Vainshtein et al. 2012) while delivering a uniform distribution of dose to the prostate. The proposed BiRT approach has the potential to spare the prostatic urethra while maintaining a high tumour control where the prostate is no longer subjected to a uniformdose. However, such an approach requires sophisticated image-guided treatment delivery that can verify the position of the urethra prior to (and potentially during) treatment. Further work in this area is required for the establishment of an appropriate urethral margin.

\section{Conclusion}

This planning study has compared uniform-dose plans with biologically-optimised IMRT plans for five PCa patients. The proposed biofocused approach utilises patient-specific tumour location and clonogen density information derived from mpMRI using a probabilistic treatment optimisation approach. Results have demonstrated that for an equivalent level of expected tumour control, a reduction in rectal and bladder dose can be achieved with the proposed BiRT methods in comparison with uniform-dose treatment planning methods.

\section{Appendix 1: Geometric errors (in $\mathbf{m m}$ )}

Target delineation [2].

$\Sigma=2 \mathrm{~mm}$ in all directions, $\mathrm{M}=0 \mathrm{~mm}$.

Fiducial marker localisation [32].

$\Sigma=1 \mathrm{~mm}$ in all directions, $\mathrm{M}=0 \mathrm{~mm}$. Intrafraction motion [32].

\begin{tabular}{llll}
\hline & $\mathrm{M}$ & $\Sigma$ & $\boldsymbol{\sigma}$ \\
\hline AP & -0.4 & 1.25 & 1.26 \\
LR & 0.2 & 1.05 & 0.67 \\
SI & 0.1 & 1.28 & 1.18 \\
\hline
\end{tabular}


MR to histology registration [49].

$\Sigma=3.3 \mathrm{~mm}$ in all directions, $\mathrm{M}=0 \mathrm{~mm}$.

MR to CT registration [13, 15, 45].

$\Sigma=2 \mathrm{~mm}$ in all directions, $\mathrm{M}=0 \mathrm{~mm}$

\section{Appendix 2: Objective functions}

$H(x)$ is a Heaviside step function:

$$
H(x)\left\{\begin{array}{c}
0, x<0 \\
1, x \geq 0
\end{array}\right.
$$

$W$ and $N$ are the assigned penalty (weighting) and the voxel number of the volume of interest.

\section{Square overdose}

$$
F=\frac{W}{N} \sum_{i=1}^{N} H\left(D_{i}-D_{r e f}\right)\left(D_{i}-D_{r e f}\right)^{2}
$$

\section{Square underdose}

$$
F=\frac{W}{N} \sum_{i=1}^{N} H\left(D_{r e f}-D_{i}\right)\left(D_{r e f}-D_{i}\right)^{2}
$$

\section{$\underline{\text { Square deviation }}$}

$$
F=\frac{W}{N} \sum_{i=1}^{N}\left(D_{i}-D_{r e f}\right)^{2}
$$

\section{Dose-volume.}

$D_{\text {ref1 }}, V_{\text {ref }}=$ desired dose-volume constraint.

$D_{\text {ref } 2}=$ current evaluation of the dose corresponding to $V_{\text {ref }}$

$$
F=\frac{W}{N} \sum_{i=1}^{N} H\left(D_{r e f 2}-D_{i}\right) H\left(D_{i}-D_{r e f 1}\right)\left(D_{i}-D_{r e f 1}\right)^{2}
$$

\section{$\underline{\text { Maximise }<T C P>}$}

$$
F=\frac{W}{N} \times-\ln (\langle T C P\rangle)
$$

\section{Supplementary information}

Supplementary information accompanies this paper at https://doi.org/10. 1186/s13014-020-01568-6.

\section{Additional file 1.}

\section{Abbreviations}

BiRT: Biofocused radiotherapy; CT: Computed tomography; CTV: Clinical target volume; DV: Dose-volume; EUD: Equivalent uniform dose; H\&E: Haematoxylin and Eosin; IMRT: Intensity-modulated radiotherapy; mpMRI: Multiparametric MRI; MRI: Magnetic resonance imaging; OAR: Organ at risk; PTV: Planning target volume; TCP: Tumour control probability

\section{Acknowledgements}

Not applicable.

\section{Authors' contributions}

EJH performed treatment planning and wrote the manuscript. HMR and YS processed and generated predictive tumour location and cell density maps from mpMRI data. AK provided DICOM file processing and performed coregistration of CT and mpMRI data. SW conducted prostate gland contouring on MRI. VP participated in data analyses and manuscript revision. $\mathrm{MB}$ provided critical support in coding biological optimisation functions in matRad. AH and MAE substantively revised and supervised this work. All authors read and approved the final manuscript.

\section{Funding}

mpMRI data collection and machine learning methods development:

- Australian National Health and Medical Research Council Grant APP1126955 (AH, SW, MAE, HMR)

- Melbourne International Research Scholarship (YS)

- Prostate Cancer Foundation of Australia Research Program - Movember

Young Investigator Grant (HMR \& YS)

- Cancer Therapeutics Top up Funding (YS)

Design of study, data analysis and interpretation of data:

- Australian Government Research Training Program Scholarship (EJH)

\section{Availability of data and materials}

The datasets generated during and/or analysed during the current study are available from the corresponding author on reasonable request.

\section{Ethics approval and consent to participate}

For this study, a subset of five patients was selected from a cohort of PCa patients who participated in a Human Research Ethics Committee approved project (Reference number: HREC/15/PMCC/125) at the Peter MacCallum Cancer Centre, Melbourne, Australia. Informed written consent was obtained from all patients.

\section{Consent for publication \\ Not applicable.}

\section{Competing interests}

The authors declare that they have no competing interests.

\section{Author details}

${ }^{1}$ School of Physics, Mathematics and Computing, University of Western Australia, Perth, Australia. ${ }^{2}$ Institute of Medical Physics, University of Sydney, Sydney, Australia. ${ }^{3}$ The Sir Peter MacCallum Department of Oncology, University of Melbourne, Melbourne, Australia. ${ }^{4}$ Department of Physical Sciences, Peter MacCallum Cancer Centre, Melbourne, Australia. ${ }^{5}$ Department of Radiation Oncology, Sir Charles Gairdner Hospital, Perth, Australia. ${ }^{6}$ Alfred Health Radiation Oncology, Melbourne, Australia. ${ }^{7}$ Department of Medical Physics in Radiation Oncology, German Cancer Research Center (DKFZ), Heidelberg, Germany. ${ }^{8}$ Department of Medical Physics in Radiation Oncology, Heidelberg Institute for Radiation Oncology, Heidelberg, Germany. ${ }^{9}$ Division of Radiation Oncology and Cancer Imaging, Peter MacCallum Cancer Centre, Melbourne, Australia. ${ }^{10} 5 \mathrm{D}$ Clinics, Perth, Australia.

Received: 19 November 2019 Accepted: 13 May 2020

Published online: 13 July 2020

\section{References}

1. Aihara M, Wheeler TM, Ohori M, Scardino PT. Heterogeneity of prostate cancer in radical prostatectomy specimens. Urology. 1994;43(1):60-6 discussion 66-67.

2. Alasti $\mathrm{H}$, Cho Y-B, Catton C, Berlin A, Chung P, Bayley A, Vandermeer A, Kong $V$, Jaffray $D$. Evaluation of high dose volumetric $C T$ to reduce interobserver delineation variability and PTV margins for prostate cancer radiotherapy. Radiother Oncol. 2017;125(1):118-23.

3. Alber M, Paulsen F, Eschmann SM, Machulla HJ. On biologically conformal boost dose optimization. Phys Med Biol. 2003;48(2):N31-5.

4. Alber M, Thorwarth D. Multi-modality functional image guided dose escalation in the presence of uncertainties. Radiother Oncol. 2014; 111(3):354-9.

5. Amdur RJ, Parsons JT, Fitzgerald LT, Million RR. The effect of overall treatment time on local control in patients with adenocarcinoma of the 
prostate treated with radiation therapy. Int J Radiat Oncol Biol Phys. 1990; 19(6):1377-82

6. Arnesen MR, Knudtsen IS, Rekstad BL, Eilertsen K, Dale E, Bruheim K, Helland $\AA$, Løndalen AM, Hellebust TP, Malinen E. Dose painting by numbers in a standard treatment planning system using inverted dose prescription maps. Acta Oncol. 2015;54(9):1607-13.

7. Azzeroni R, Maggio A, Fiorino C, Mangili P, Cozzarini C, De Cobelli F, Di Muzio NG, Calandrino R. Biological optimization of simultaneous boost on intra-prostatic lesions (DILs): sensitivity to TCP parameters. Physica Medica. 2013;29(6):592-8.

8. Berwouts D, Olteanu LAM, Duprez F, Vercauteren T, De Gersem W, De Neve W, Van de Wiele C, Madani I. Three-phase adaptive dose-painting-bynumbers for head-and-neck cancer: initial results of the phase I clinical trial. Radiother Oncol. 2013;107(3):310-6.

9. Betts JM, Mears C, Reynolds HM, Ebert MA, Haworth A. Prostate cancer focal brachytherapy: improving treatment plan robustness using a convolved dose rate model. Int Conf Comput Sci, ICCS 2017, 12-14 June 2017, Zurich, Switzerland. 2017;108:1522-31.

10. Betts JM, Mears C, Reynolds HM, Tack G, Leo K, Ebert MA, Haworth A. Optimised Robust Treatment Plans for Prostate Cancer Focal Brachytherapy. Procedia Comput Sci. 2015:51(Supplement C):914-23.

11. Bohoslavsky R, Witte MG, Janssen TM, van Herk M. Probabilistic objective functions for margin-less IMRT planning. Phys Med Biol. 2013; 58(11):3563-80.

12. Cisternas $E$, Mairani $A$, Ziegenhein $P$, Jäkel $O$, Bangert $M$. matRad - a multimodality open source 3D treatment planning toolkit. In: Jaffray DA, editor. World congress on medical physics and biomedical engineering, June 7-12, 2015, Toronto, Canada. Cham: Springer International Publishing; 2015. p. 1608-11.

13. Dean CJ, Sykes JR, Cooper RA, Hatfield P, Carey B, Swift S, Bacon SE, Thwaites D, Sebag-Montefiore D, Morgan AM. An evaluation of four CT-MRI co-registration techniques for radiotherapy treatment planning of prone rectal cancer patients. Br J Radiol. 2012;85(1009):61-8.

14. Differding S, Sterpin E, Hermand N, Vanstraelen B, Nuyts S, de Patoul N, Denis J-M, Lee JA, Grégoire V. Radiation dose escalation based on FDG-PET driven dose painting by numbers in oropharyngeal squamous cell carcinoma: a dosimetric comparison between TomoTherapy-HA and RapidArc. Radiat Oncol. 2017;12:1.

15. Dinis Fernandes C, Dinh CV, Steggerda MJ, ter Beek LC, Smolic M, van Buuren LD, Pos FJ, van der Heide UA. Prostate fiducial marker detection with the use of multi-parametric magnetic resonance imaging. Phys Imaging Radiat Oncol. 2017;1:14-20.

16. Dirscherl T, Rickhey M, Bogner L. Feasibility of TCP-based dose painting by numbers applied to a prostate case with 18F-choline PET imaging. Z Med Phys. 2012;22(1):48-57.

17. Ebert MA, Hoban PW. Some characteristics of tumour control probability for heterogeneous tumours. Phys Med Biol. 1996;41(10):2125-33.

18. Flynn RT, Bowen SR, Bentzen SM, Mackie TR, Jeraj R. Intensity modulated xray (IMXT) vs. proton (IMPT) therapy for theragnostic hypoxia-based dose painting. Phys Med Biol. 2008;53(15):4153-67.

19. Fowler JF, Ritter MA, Fenwick JD, Chappell RJ. How low is the $\alpha / \beta$ ratio for prostate cancer? In regard to Wang et al., IJROBP 2003;55:194-203. Int J Radiat Oncol Biol Phys. 2003;57(2):593-5.

20. Gao M, Mayr NA, Huang Z, Zhang H, Wang JZ. When tumor repopulation starts? The onset time of prostate cancer during radiation therapy. Acta Oncologica. 2010;49(8):1269-75.

21. García-Figueiras R, Baleato-González S, Padhani AR, Luna-Alcalá A, VallejoCasas JA, Sala E, Vilanova JC, Koh D-M, Herranz-Carnero M, Vargas HA. How clinical imaging can assess cancer biology. Insights Imaging. 2019;10(1):28.

22. Grönlund E, Johansson S, Montelius A, Ahnesjö A. Dose painting by numbers based on retrospectively determined recurrence probabilities. Radiother Oncol. 2017;122(2):236-41.

23. Haworth A, Ebert M, Waterhouse D, Joseph D, Duchesne G. Assessment of i125 prostate implants by tumor bioeffect. Int J Radiat Oncol Biol Phys. 2004a;59(5):1405-13.

24. Haworth A, Ebert M, Waterhouse D, Joseph D, Duchesne G. Prostate implant evaluation using tumour control probability - the effect of input parameters. Phys Med Biol. 2004b;49(16):3649-64.

25. Haworth A, Mears C, Betts JM, Reynolds HM, Tack G, Leo K, Williams S, Ebert MA. A radiobiology-based inverse treatment planning method for optimisation of permanent $1-125$ prostate implants in focal brachytherapy. Phys Med Biol. 2016;61(1):430-44.
26. Haworth A, Sun Y, Ebert M, Reynolds H, Betts J, Wraith D, Mitchell C. Incorporating a Novel Radiomics Framework for Biologically Optimised Prostate RadioTherapy (BiRT). Med Phys. 2018;45(6):E446.

27. van Herk M, Remeijer P, Rasch C, Lebesque JV. The probability of correct target dosage: dose-population histograms for deriving treatment margins in radiotherapy. Int J Radiat Oncol Biol Phys. 2000;47(4):1121-35.

28. Herschorn S, Elliott S, Coburn M, Wessells H, Zinman L. SIU/ICUD consultation on urethral strictures: posterior urethral stenosis after treatment of prostate cancer. Urology. 2014;83(3 Suppl):S59-70.

29. Keall PJ, Webb S. Optimum parameters in a model for tumour control probability, including interpatient heterogeneity: evaluation of the lognormal distribution. Phys Med Biol. 2007;52(1):291-302.

30. Khourdaji I, Parke J, Chennamsetty A, Burks F. Treatment of urethral strictures from irradiation and other nonsurgical forms of pelvic Cancer treatment. Adv Urol. 2015;2015:476390.

31. Kong F, Ten Haken RK, Schipper MJ, Hayman J, Ramnath N, Hassan KA, Matuszak M, Ritter T, Bi N, Wang W, Orringer M, Cease KB, Lawrence TS, Kalemkerian GP. A phase II trial of mid-treatment FDG-PET adaptive, individualized radiation therapy plus concurrent chemotherapy in patients with non-small cell lung cancer (NSCLC). J Clin Oncol. 2013; 31(15_suppl):7522.

32. Kron T, Thomas J, Fox C, Thompson A, Owen R, Herschtal A, Haworth A, Tai $\mathrm{K}-\mathrm{H}$, Foroudi F. Intra-fraction prostate displacement in radiotherapy estimated from pre- and post-treatment imaging of patients with implanted fiducial markers. Radiother Oncol. 2010;95(2):191-7.

33. Lai PP, Pilepich MV, Krall JM, Asbell SO, Hanks GE, Perez CA, Rubin P, Sause WT, Cox JD. The effect of overall treatment time on the outcome of definitive radiotherapy for localized prostate carcinoma: the radiation therapy oncology group 75-06 and 77-06 experience. Int J Radiat Oncol Biol Phys. 1991;21(4):925-33.

34. Landberg T, Chavaudra J, Dobbs J, Gerard J-P, Hanks G, Horiot J-C, Johansson K-A, Möller T, Purdy J, Suntharalingam N, Svensson H. Report 62. J Int Comm Radiat Units Meas. 1999;0s32:1.

35. Lawton CA, Bae K, Pilepich M, Hanks G, Shipley W. Long-term treatment sequelae after external beam irradiation with or without hormonal manipulation for adenocarcinoma of the prostate: analysis of radiation therapy oncology group studies 85-31, 86-10, and 92-02. Int J Radiat Oncol Biol Phys. 2008;70(2):437-41.

36. Lawton CAF, Michalski J, El-Naqa I, Buyyounouski MK, Lee WR, Menard C, O'Meara E, Rosenthal SA, Ritter M, Seider M. RTOG GU radiation oncology specialists reach consensus on pelvic lymph node volumes for high-risk prostate Cancer. Int J Radiat Oncol Biol Phys. 2009;74(2):383-7.

37. Lips IM, van der Heide UA, Haustermans K, van Lin EN, Pos F, Franken SP, Kotte AN, van Gils $\mathrm{CH}, \mathrm{M}$ van V. Single blind randomized Phase III trial to investigate the benefit of a focal lesion ablative microboost in prostate cancer (FLAME-trial): study protocol for a randomized controlled trial. Trials. 2011;12(1):255.

38. Madani I, Duthoy W, Derie C, Gersem WD, Boterberg T, Saerens M, Jacobs F, Grégoire V, Lonneux M, Vakaet L, Vanderstraeten B, Bauters W, Bonte K, Thierens H, Neve WD. Positron emission tomography-guided, focal-dose escalation using intensity-modulated radiotherapy for head and neck Cancer. Int J Radiat Oncol Biol Phys. 2007;68(1):126-35.

39. Michalski JM, Gay H, Jackson A, Tucker SL, Deasy JO. Radiation dose-volume effects in radiation-induced rectal injury. Int J Radiat Oncol Biol Phys. 2010; 76(3):S123-9.

40. Moore JA, Gordon JJ, Anscher M, Silva J, Siebers JV. Comparisons of treatment optimization directly incorporating systematic patient setup uncertainty with a margin-based approach: systematic probabilistic treatment planning comparisons. Med Phys. 2012;39(2):1102-11.

41. Movsas B, Chapman JD, Greenberg RE, Hanlon AL, Horwitz EM, Pinover WH, Stobbe C, Hanks GE. Increasing levels of hypoxia in prostate carcinoma correlate significantly with increasing clinical stage and patient age: an Eppendorf pO(2) study. Cancer. 2000;89(9):2018-24.

42. Movsas B, Chapman JD, Hanlon AL, Horwitz EM, Greenberg RE, Stobbe C, Hanks GE, Pollack A. Hypoxic prostate/muscle $\mathrm{pO} 2$ ratio predicts for biochemical failure in patients with prostate cancer: preliminary findings. Urology. 2002;60(4):634-9.

43. Niemierko A. A generalized concept of equivalent uniform dose (EUD). Med Phys. 1999;26(6):1100.

44. Orlandi M, Botti A, Sghedoni R, Cagni E, Ciammella P, lotti C, lori M. Feasibility of voxel-based dose painting for recurrent Glioblastoma guided 
by ADC values of diffusion-weighted MR imaging. Physica Medica. 2016; 32(12):1651-8.

45. Parker CC, Damyanovich A, Haycocks T, Haider M, Bayley A, Catton CN Magnetic resonance imaging in the radiation treatment planning of localized prostate cancer using intra-prostatic fiducial markers for computed tomography co-registration. Radiother Oncol. 2003;66(2):217-24.

46. Perez CA, Michalski J, Mansur D, Lockett MA. Impact of elapsed treatment time on outcome of external-beam radiation therapy for localized carcinoma of the prostate. Cancer J (Sudbury, Mass.). 2004;10(6):349-56.

47. Ragde H, Blasko JC, Grimm PD, Kenny GM, Sylvester JE, Hoak DC, Landin K, Cavanagh W. Interstitial iodine-125 radiation without adjuvant therapy in the treatment of clinically localized prostate carcinoma. Cancer. 1997;80(3): 442-53.

48. Rasmussen JH, Håkansson K, Vogelius IR, Aznar MC, Fischer BM, Friborg J, Loft A, Kristensen CA, Bentzen SM, Specht L. Phase I trial of 18F-

Fludeoxyglucose based radiation dose painting with concomitant cisplatin in head and neck cancer. Radiother Oncol. 2016;120(1):76-80.

49. Reynolds HM, Williams S, Zhang A, Chakravorty R, Rawlinson D, Ong CS, Esteva M, Mitchell C, Parameswaran B, Finnegan M. Development of a registration framework to validate MRI with histology for prostate focal therapy. Med Phys. 2015;42(12):7078-89.

50. Rickhey M, Morávek Z, Eilles C, Koelbl O, Bogner L. 18F-FET-PET-based dose painting by numbers with protons. Strahlenther Onkol. 2010;186(6):320-6.

51. van Schie MA, Dinh CV, van Houdt PJ, Pos FJ, Heijmink SWTJP, Kerkmeijer LGW, Kotte ANTJ, Oyen R, Haustermans K, van der Heide UA. Contouring of prostate tumors on multiparametric MRl: evaluation of clinical delineations in a multicenter radiotherapy trial. Radiother Oncol. 2018;128(2):321-6.

52. van Schie MA, Steenbergen P, Dinh CV, Ghobadi G, van Houdt PJ, Pos FJ, Heijmink SWTJP, van der Poel HG, Renisch S, Vik T, van der Heide UA. Repeatability of dose painting by numbers treatment planning in prostate cancer radiotherapy based on multiparametric magnetic resonance imaging. Phys Med Biol. 2017;62(14):5575-88.

53. Sun Y, Reynolds H, Wraith D, Williams S, Finnegan ME, Mitchell C, Murphy D, Ebert MA, Haworth A. Predicting prostate tumour location from multiparametric MRI using Gaussian kernel support vector machines: a preliminary study. Australas Phys Eng Sci Med. 2017a;40(1):39-49.

54. Sun Y, Reynolds HM, Wraith D, Williams S, Finnegan ME, Mitchell C, Murphy D, Haworth A. Voxel-wise prostate cell density prediction using multiparametric magnetic resonance imaging and machine learning. Acta Oncol. 2018;57(11):1540-46. https://doi.org/10.1080/0284186X.2018.1468084.

55. Sun Y, Reynolds HM, Wraith D, Williams S, Finnegan ME, Mitchell C, Murphy D, Haworth A. Automatic stratification of prostate tumour aggressiveness using multiparametric MRI: a horizontal comparison of texture features. Acta Oncol. 2019;58(8):1118-26. https://doi.org/10.1080/0284186X.2019.15985761.

56. Sun Y, Williams S, Byrne D, Keam S, Reynolds HM, Mitchell C, Wraith D, Murphy D, Haworth A. Association analysis between quantitative MRI features and hypoxia-related genetic profiles in prostate cancer: a pilot study. Br J Rad. 2019;92(1104):20190373.

57. Thorwarth D, Eschmann S-M, Paulsen F, Alber M. Hypoxia dose painting by numbers: a planning study. Int J Radiat Oncol Biol Phys. 2007;68(1):291-300.

58. Thorwarth D, Notohamiprodjo M, Zips D, Müller A-C. Personalized precision radiotherapy by integration of multi-parametric functional and biological imaging in prostate cancer: a feasibility study. Zeitschrift Fur Medizinische Physik. 2017;27(1):21-30.

59. Unkelbach J, Alber M, Bangert M, Bokrantz R, Chan TCY, Deasy JO, Fredriksson A, Gorissen BL, Herk M, Liu W, Mahmoudzadeh H, Nohadani O, Siebers JV, Witte M, Xu H. Robust radiotherapy planning. Phys Med Biol. 2018:63(22):22TR02.

60. Vanderstraeten B, Duthoy W, Gersem WD, Neve WD, Thierens H. [18F]fluorodeoxy-glucose positron emission tomography ([18F]FDG-PET) voxel intensity-based intensity-modulated radiation therapy (IMRT) for head and neck cancer. Radiother Oncol. 2006;79(3):249-58.

61. Viswanathan AN, Yorke ED, Marks LB, Eifel PJ, Shipley WU. Radiation dosevolume effects of the urinary bladder. Int J Radiat Oncol Biol Phys. 2010;76(3 Suppl):S116-22.

62. Wahl N, Hennig P, Wieser H-P, Bangert M. Analytical incorporation of fractionation effects in probabilistic treatment planning for intensitymodulated proton therapy. Med Phys. 2018;45(4):1317-28.

63. Wang JZ, Guerrero M, Li XA. How low is the alpha/beta ratio for prostate cancer? Int J Radiat Oncol Biol Phys. 2003a:55(1):194-203.
64. Wang JZ, Guerrero M, Li XA. Low $\alpha / \beta$ ratio for prostate cancer: in response to Dr. Fowler et al. Int J Radiat Oncol Biol Phys. 2003b;57(2):595-6.

65. Welz S, Mönnich D, Pfannenberg C, Nikolaou K, Reimold M, La Fougère $C$, Reischl G, Mauz P-S, Paulsen F, Alber M, Belka C, Zips D, Thorwarth D. Prognostic value of dynamic hypoxia PET in head and neck cancer: results from a planned interim analysis of a randomized phase II hypoxia-image guided dose escalation trial. Radiother Oncol. 2017;124(3):526-32.

66. Wieser H, Cisternas E, Wahl N, Ulrich S, Stadler A, Mescher H, Müller L-R, Klinge T, Gabrys H, Burigo L. Development of the open-source dose calculation and optimization toolkit matRad. Med Phys. 2017;44(6):2556-68. https://doi.org/10.1002/mp.12251.

67. Witte MG, van der Geer J, Schneider C, Lebesque JV, Alber M, van Herk M. IMRT optimization including random and systematic geometric errors based on the expectation of TCP and NTCP: optimization of expected TCP and NTCP. Med Phys. 2007:34(9):3544-55.

68. Yamin G, Schenker-Ahmed NM, Shabaik A, Adams D, Bartsch H, Kuperman J, White NS, Rakow-Penner RA, McCammack K, Parsons JK, Kane CJ, Dale AM, Karow DS. Voxel level radiologic-pathologic validation of restriction Spectrum imaging cellularity index with Gleason grade in prostate Cancer. Clin Cancer Res. 2016;22(11):2668-74.

69. Yan D, Chen S, Krauss DJ, Chen PY, Chinnaiyan P, Wilson GD. Tumor voxel dose-response matrix and dose prescription function derived using $18 \mathrm{~F}$ FDG PET/CT images for adaptive dose painting by number. Int I Radiat Oncol Biol Phys. 2019;104(1):207-18.

\section{Publisher's Note}

Springer Nature remains neutral with regard to jurisdictional claims in published maps and institutional affiliations.

Ready to submit your research? Choose BMC and benefit from:

- fast, convenient online submission

- thorough peer review by experienced researchers in your field

- rapid publication on acceptance

- support for research data, including large and complex data types

- gold Open Access which fosters wider collaboration and increased citations

- maximum visibility for your research: over $100 \mathrm{M}$ website views per year

At BMC, research is always in progress.

Learn more biomedcentral.com/submissions 